\title{
Do jornalismo online ao webjornalismo: formação para a mudança
}

\author{
João Manuel Messias Canavilhas ${ }^{1}$
}

\section{Resumo}

O jornalismo online em Portugal ainda se encontra numa fase inicial de desenvolvimento. As versões online dos media tradicionais são muito semelhantes às versões impressas. Algumas delas usam ferramentas específicas da web, mas ainda estão muito aquém de tirarem o máximo proveito das suas potencialidades. Com relação à formação dos futuros jornalistas digitais, o maior desafio é transmitir aos jornalistas conhecimentos teóricos e técnicos, especialmente adaptados ao ambiente $w e b$, bem como às suas possibilidades. Dentro deste cenário, as instituições de ensino superior tem um papel fundamental, uma vez que é daqui que sai a maior arte dos jornalistas online $(77,8 \%)$. As universidades devem desempenhar um importante papel a desenvolver uma linguagem jornalística especialmente para a Internet, desenvolvendo investigação neste sentido e criando modelos económicos para trazer alguma viabilidade económica à informação online.

Palavras-chave: jornalismo digital, media, Internet, ensino do jornalismo online.

\section{Introdução}

Em 2005 cumpre-se uma década de jornalismo online em Portugal. Ao longo deste período, jornais, rádios e televisões entraram em força na Internet, mas muitos deles utilizam-na apenas como suporte. Registou-se ainda o aparecimento de publicações exclusivamente online, como o Diário Digital ou o Portugal Diário mas, no essencial, estas publicações mantêm as características de um jornal tradicional.

As publicações online portuguesas têm algumas marcas de uma nova linguagem, mas ficam bastante aquém das potencialidades oferecidas pela web. A dificuldade em encontrar um modelo de negócio que viabilize estes projectos é o grande entrave ao seu desenvolvimento, com repercussões, por exemplo, na dificuldade em contratar 
profissionais qualificados, o que impede o rápido desenvolvimento de um modelo mais consentâneo com as características da web.

Cabrera Gonzalez (2000) identifica quatro modelos de jornal online que correspondem a outras tantas fases de evolução.

Uma primeira, denominada fac-simile, corresponde à reprodução simples de páginas da versão impressa de um jornal, quer através da sua digitalização, quer através de um PDF.

Numa segunda fase - modelo adaptado - os conteúdos ainda são os mesmos das versões escritas dos jornais, mas a informação é apresentada num layout próprio. Nesta fase começam a ser integrados links nos textos.

$\mathrm{Na}$ terceira fase - modelo digital - os jornais têm um layout pensado e criado para o meio online. A utilização do hipertexto e a possibilidade de comentar são presença obrigatória e as notícias de última hora passam a ser um factor de diferenciação em relação às versões em papel.

Por fim, o modelo multimédia, corresponde a uma fase em que as publicações tiram o aproveitamento máximo das características do meio, nomeadamente a interactividade e a possibilidade de integrar som, vídeo e animações nas notícias.

A categorização proposta por Cabrera González parece resultar da observação de publicações online nascidas em grupos de comunicação proprietários de jornais em papel, a situação mais vulgar no meio. Se quisermos alargar esta sistematização a todos os meios de comunicação, podemos restringir o processo a duas fases fundamentais: jornalismo online e webjornalismo/ciberjornalismo.

No primeiro caso, as publicações mantêm as características essenciais dos meios que lhes deram origem. No caso dos jornais, as versões online acrescentam a actualização constante, o hipertexto para ligações a notícias relacionadas e a possibilidade de comentar as notícias. No caso das rádios, a emissão está disponível online, são acrescentadas algumas notícias escritas e disponibilizam-se a programação e os contactos. As televisões têm também informação escrita, à qual são acrescentadas notícias em vídeo, a programação do canal e os contactos.

Como se pode verificar, trata-se de uma simples transposição do modelo existente no seu ambiente tradicional para um novo suporte.

$\mathrm{Na}$ fase a que chamamos webjornalismo/ciberjornalismo, as notícias passam a ser produzidas com recurso a uma linguagem constituída por palavras, sons, vídeos, infografias e hiperligações, tudo combinado de forma a que o utilizador possa escolher o seu próprio percurso de leitura.

O jornalismo na web que actualmente se faz em Portugal encontra-se ainda na primeira fase de desenvolvimento. As publicações existentes funcionam como uma espécie de jornalismo de agência, ao qual se juntam hipertexto, arquivo, artigos de opinião e a possibilidade de contactar os jornalistas. Noutros casos, as versões online de meios tradicionais têm características muito semelhantes às das suas versões tradicionais, tirando partido de algumas características da web mas, ainda assim, muito longe de explorarem as potencialidades do meio. 


\section{Formação actual dos jornalistas}

Num trabalho em curso intitulado "Retrato dos jornalistas online em Portugal", cujos resultados serão apresentados no congresso deste ano da SOPCOM, foram inquiridos 54 jornalistas que trabalham no online com o objectivo de saber que formação tiveram. Os resultados preliminares revelam que a formação na empresa é a situação mais habitual entre os profissionais que trabalham no online, com $53,7 \%$ dos inquiridos a referir este tipo de formação. Destes, $77,3 \%$ teve formação em actividade, contra apenas $22,7 \%$ que adquiriu competências nesta área em cursos organizados pela empresa.

Os restantes inquiridos receberam formação específica no Ensino Superior $(16,7 \%)$ ou no Cenjor (9,3\%). Há ainda 33,3\% de jornalistas que dizem não ter recebido qualquer tipo de formação.

A baixa percentagem de jornalistas que recebeu formação no Ensino Superior, em conjunto com a constatação de que a formação é importante, levam $94,4 \%$ dos inquiridos a considerar que a opção de jornalismo online deve ser introduzida no curriculum das escolas.

Actualmente, uma disciplina de jornalismo online é ministrada em seis escolas, embora com denominações diferentes: ciberjornalismo, jornalismo online, jornalismo em linha, oficina de jornalismo digital ou atelier de jornalismo online são alguns exemplos de disciplinas oferecidas pelas escolas portuguesas. Noutros casos, o jornalismo online é estudado em disciplinas que abordam a temática digital.

Inquiridos acerca dos programas informáticos que utilizam, os jornalistas referem os processadores de texto $(96,3 \%)$, seguindo-se os programas de tratamento digital de fotografias $(87 \%)$, as folhas de cálculo $(31,5 \%)$, animação vectorial $(16,6 \%)$, edição de som $(14,8 \%)$, edição de HTML $(12,9 \%)$, edição de vídeo $(7,4 \%)$ e edição electrónica $(5,6 \%)$. Apesar de a utilização de ferramentas de autor se restringir a um pequeno grupo, $88,9 \%$ dos inquiridos considera importante o domínio deste tipo de aplicações.

Por opção da empresa ou por falta de formação, os hipermédia ainda são pouco utilizados nas publicações portuguesas. Apenas $68,5 \%$ dos jornalistas integra hipertexto nos seus artigos, embora $74,1 \%$ considere que se trata de um bom auxiliar na hora de construir a notícia.

A inclusão de vídeo ou som na notícia é mais rara, com $44,4 \%$ a referirem a sua utilização.

As percentagens referidas num e noutro caso são interessantes, porém a realidade parece ser algo diferente. A análise das publicações onde trabalham estes jornalistas permite observar que raramente o som e o vídeo fazem parte da notícia. Normalmente são oferecidos como complemento da notícia e quase exclusivamente pelas edições online dos meios que, na sua versão tradicional, oferecem este tipo de formato. A TSF Online, por exemplo, disponibiliza sons, tal como a SIC Online disponibiliza vídeos.

Já o hipertexto é mais vulgar nas publicações portuguesas. Apesar disso, a sua utilização fica-se pela referência a notícias anteriores relacionadas com o assunto. Mais do que uma contextualização, serve para sinalizar o percurso de um acontecimento. 


\section{Formar webjornalistas}

A esmagadora maioria dos jornalistas que trabalha na área do online $(90,7 \%)$ considera que a web é um novo meio de comunicação social. Quando questionados se o jornalismo online será apenas uma moda, os números são ainda mais expressivos, com $98,1 \%$ a discordarem.

E se do lado da emissão os números são interessantes, do lado da recepção o panorama também é animador. Os dados preliminares de um estudo em curso na Universidade da Beira Interior revelam que 17,9\% dos estudantes referem a Internet como fonte de $25 \%$ a $50 \%$ das notícias que consomem diariamente, e $10,7 \%$ diz que mais de metade das notícias é originária da Internet.

Havendo um mercado potencial, a evolução do jornalismo na web depende do tal modelo económico que permitirá financiar as publicações. No estudo A Internet e a Imprensa em Portugal, publicado em 2003, são identificadas algumas razões que levariam os consumidores a pagar informação online e, entre elas, destacam-se a personalização da informação, o desejo de aceder a informação com suporte multimédia, a actualização permanente da informação e a possibilidade de trocar informações com os jornalistas.

\subsection{Constrangimentos}

2.1.1 Recepção - Um dos entraves ao jornalismo na web é o tipo de acesso. O recurso aos hipermédia vai exigir acesso mais rápido e sabe-se que, apesar do rápido crescimento dos últimos anos, o número de lares com ligações ADSL ainda é pouco significativo.

Um outro problema está relacionado com as competências que o leitor deverá ter para conseguir descodificar conteúdos multimédia. A introdução de uma nova linguagem implica o domínio de novas competências narrativas, linguísticas, iconográficas e estéticas o que, provavelmente, vai levar algum tempo. No estudo que decorre na UBI, referido anteriormente, detectou-se que o facto de as palavras linkadas não aparecerem sublinhadas, por exemplo, faz com que os utilizadores não sigam esses mesmos links. Detectou-se igualmente que a transformação do cursor do rato numa mão ainda não é associado a uma zona interactiva. Estes são apenas dois exemplos do trabalho que ainda terá de ser feito ao nível das competências dos utilizadores.

2.1.2 Emissão - As maiores dificuldades neste campo estão relacionadas com questões financeiras. Passado todo este tempo, ainda não foi possível encontrar um modelo de negócio que viabilize as publicações online. Até agora foram testados três modelos: o pagamento do acesso à informação, o acesso gratuito às últimas edições mas com necessidade de registo (financiamento através de publicidade dirigida) e o acesso sem restrições, onde o financiamento depende da publicidade e da venda de conteúdos.

Esta dificuldade em encontrar fontes de financiamento levou as empresas a reduzirem o investimento em recursos humanos, com a consequente subvalorização do potencial do meio. 
2.1.3 Investigação - Um outro nível de constrangimentos está relacionado com a investigação desenvolvida no Ensino Superior. Apesar de existir já uma produção científica significativa, falta passar à fase experimental. Só assim será possível desenvolver modelos de notícia multimédia que responda às expectativas dos utilizadores.

\subsection{Desafios}

Há um conjunto de desafios que não dependem da formação, pelo que nos cingiremos à questão da formação. Até porque, naturalmente, alguns desses desafios estão relacionados com o grau de desenvolvimento tecnológico do país.

Ao nível da formação, o grande desafio é dotar os jornalistas de conhecimentos teóricos e práticos directamente ligados àquelas que são as características fundamentais do jornalismo na web. Neste campo, o Ensino Superior tem um papel importante, já que é deste grau de ensino que saem a maioria $(77,8 \%)$ dos profissionais que trabalham no online.

Por isso propõe-se a criação de uma especialização em ciberjornalismo/webjornalismo, com a integração de disciplinas ligadas àquelas que são as características fundamentais do jornalismo na web.

Multimédia - Ao integrar infografias, vídeos e sons, o webjornalismo implica conhecimentos técnicos nos campos do tratamento de imagem, animação vectorial, edição de vídeo/som e html.

O objectivo é fazer com que o jornalista possa produzir alguns dos conteúdos mas, sobretudo, dotá-lo de uma linguagem técnica capaz de lhe permitir desenhar o produto final e coordenar a equipa de produção de conteúdos.

Neste campo, parte da formação técnica pode ser semelhante aquela que é ministrada no jornalismo radiofónico ou no jornalismo televisivo, pois as ferramentas para edição de vídeo e som acabam por ser as mesmas. Para além destas duas áreas comuns, a formação deve ainda incluir um módulo de edição de HTML e outro de animação vectorial. Nesse sentido, propõe-se a inclusão de uma disciplina denominada Ferramentas de Autor Multimédia.

Para além da produção dos conteúdos multimédia, é necessário saber onde, quando e como devem ser integrados estes elementos, pelo que se justifica uma disciplina denominada Gramática Multimédia.

Hipertextual e Interactivo - A redacção de notícias com hipertexto requer todo um novo sistema de construção. A tradicional técnica "pirâmide invertida" dá lugar a uma arquitectura noticiosa mais aberta, com blocos de informação organizados em diferentes modelos, sejam eles lineares ou complexos.

O elemento base da notícia, um primeiro nível onde todos os utilizadores iniciam o seu percurso de leitura, deve ser um parágrafo ou uma infografia que responda de forma simplificada ao Quem, Onde, O quê e Quando. A partir deste elemento, que deverá incluir links, a notícia evolui de forma livre para o Como e o Porquê, com o 
utilizador a escolher o seu percurso de leitura. No fundo, a produção da notícia deverá ter como base um guião muito semelhante ao de um jogo, prevendo todas as possibilidades de leitura, pelo que se justifica a introdução de uma disciplina denominada Técnicas de Redacção com Hipertexto.

Outras duas características habitualmente ligadas ao jornalismo na web - personalização e memória - serão o resultado da integração do sistema de edição numa base de dados. Um e outro caso remetem para a necessidade de classificar as notícias, enquanto unidades de significação jornalística.

A personalização é conseguida através do registo do utilizador numa determinada publicação ou através da instalação de cookies no seu browser. Neste caso, trata-se de um processo meramente informático no qual o jornalista não tem intervenção.

Já a memória representa muito mais do que o simples arquivo e é uma questão fundamental num jornalismo onde o espaço que a notícia ocupa não é um bem escasso. A possibilidade de ligar uma nova notícia aos seus antecedentes permite o enriquecimento do jornalismo graças à contextualização dos fenómenos. Este jornalismo mais informado contraria a tendência actual de um jornalismo de estados de alma e poderá contribuir de forma decisiva para a recuperação do prestígio que a actividade tem vindo a perder.

Estas questões de cariz mais abrangente poderão ser abordadas numa disciplina mais genérica como as que já existem - Ciberjornalismo ou webjornalismo - mas a autonomização de algumas matérias permitirá que o fenómeno do online tenha uma abordagem teórica mais aprofundada.

\section{Conclusão}

É sabido que os meios de comunicação tiveram diferentes períodos de maturação, sendo que o mais recente - a televisão - evoluiu mais rapidamente que a rádio, e esta mais rapidamente que a imprensa. Nesta perspectiva, a Internet terá estádios de evolução ainda mais rápidos. Aliás, basta olhar para o que aconteceu na última década para se perceberem mudanças que há dez anos atrás eram impensáveis.

O Ensino Superior tem um papel preponderante no desenvolvimento de uma linguagem jornalística própria para a web, podendo oferecer o seu contributo a dois níveis.

Por um lado, promovendo a investigação no sentido de se encontrar uma linguagem para este novo meio. Por outro, desenvolvendo modelos económicos que permitam viabilizar a informação na web. Só desta forma as empresas deixarão de ver o sector do online como uma segunda linha do jornalismo, uma espécie de montra de baixo custo cujo único objectivo é promover o jornal, a rádio ou a televisão que suporta o meio online.

A viabilização dos projectos online e a necessidade de desenvolver novos produtos levará as empresas às escolas, fechando-se assim o ciclo formação/economia. 


\section{Bibliografia}

Bastos, H. (2000) Jornalismo Electrónico, Coimbra: Minerva.

Canavilhas, J. A (2004) 'Notícia no webjornalismo: arquitectura e leitura da imagem' 152-171 in Brasil A.; Alzamora G. et al. (org.) (2004) Cultura em Fluxo: Novas mediações em rede, Minas Gerais: PUCMinas.

Salaverria, R. (2005) Redacción Periodística en Internet, Pamplona: EUNSA.

Pavlik, J. (2001) Journalism and New Media, New Cork: Columbia University Press.

Traquina, N. (2002) Jornalismo, Lisboa: Quimera.

Valcarce, D. P. \& Marcos, J. A. (2004) Ciberperiodismo, Madrid: Síntesis.

Ward, M. (2002) Journalism Online, Oxford: FocalPress.

\section{Textos online}

Barbosa, S. [2004] Identificando Remediações e Rupturas no Uso de Bancos de Dados no Jornalismo Digital em http://webjornalismo.com/sections.php?op=viewarticle\&artid=96, consultado em $25 \mathrm{de}$ Maio de 2005.

Canavilhas, J. [2003] Webjornalismo: Novo Media, Nova Linguagem em http://www.webjornalismo.com/ sections.php?op=viewarticle\&artid=6, consultado em 12 de Maio de 2005.

Cabrera González, M.A. [2000] Convivencia de la Prensa Escrita y la Prensa Online en su Transición hacia el Modelo de Comunicación Multimedia em http://www.ucm.es/info/periol/Period_I/EMP/Numer_07/74-Comu/7-4-01.htm, consultado em 15 de Maio de 2005.

Mielniczuk, L. [2001] Características e Implicações do Jornalismo na Web. Em http://www.webjornalismo. com/sections.php?op=viewarticle\&artid=22, consultado em 16 de Maio de 2005.

\section{Estudos online}

A Internet e a Imprensa em Portugal - Estudo da Vector XXI.

http://www.vector21.com/pd/estudosmercado/ consultado em 8 de Setembro de 2004. 